\title{
Mckittrick-Wheelock syndrome: an often, overlooked complication of rectal adenomas
}

\author{
Shailendra Kapoor
}

Received: 27 October 2013/Accepted: 27 December 2013/Published online: 27 March 2014

(C) Springer Science+Business Media New York 2014

\section{To the Editor}

One [1] rare but serious complication of rectal adenomas that is often overlooked is McKittrick-Wheelock syndrome (MKWS).

The syndrome typically incorporates the signs and symptoms secondary to the accentuated secretion of fluids from a rectal villous adenoma. For instance, Barendse et al. [2] recently reported two cases, both of whom presented with renal failure and were later found to have giant rectal adenomas. The rectal adenomas usually measure greater than $4 \mathrm{~cm}$ in size. The typical triad of MKWS includes renal failure and electrolytic imbalance in the setting of chronic diarrhea due to an underlying villous adenoma [3]. The larger and more distal the adenoma, the more severe the syndrome. The hypersecretion may be so severe that severe azotemia may result [4].

The syndrome is a secondary to accentuated secretion of PG-E2 by the rectal adenoma. Hypokalemia and hyponatremia are frequently seen. Altered mental status may occur in severe cases of MKWS [5]. Oliguria is usually present. Profuse mucous diarrhea is typical. Severe rhabdomyolysis may also occur. Severe cases may progress to hypokalemic and hypochloremic 'high anion' gap metabolic acidosis. Rarely, colonic-pseudo obstruction may occur as recently reported by Wakeman [6].

Immediate and aggressive replacement of fluids and electrolytes is deemed necessary once the diagnosis of MKWS is made [7]. The renal failure usually improves following endoscopic mucosal resection of the rectal adenoma [8]. Choi et al. [9] recently reported the successful use

S. Kapoor $(\square)$

Chicago, IL, USA

e-mail: shailendrakapoor@yahoo.com of laparoscopic low anterior surgical resection. The cyclooxygenase inhibitor indomethacin is also of some value in the management of MKWS.

MKWS needs to be treated as soon as diagnosis is made, as cardiac arrhythmias may result, which may result in significant mortality. There is a need to increase awareness about MKWS amongst physicians, especially surgeons.

\section{References}

1. Sallinen V, Santti H, Liukkonen T et al (2013) Safety and longterm results of endoscopic transanal resection in treating rectal adenomas: 15 years' experience. Surg Endosc 27(9):3431-3436

2. Barendse R, van den Brandt S, Dekker E, Fockens P (2013) McKittrick-Wheelock syndrome [Dutch]. Ned Tijdschr Geneeskd 157(3):A5567

3. Skuta R, Danaj M, Duda I, Dobrovodsky A (2012) McKittrickWheelock syndrome: complication of rectal mucinous adenoma. Rozhl Chir 91:246-248

4. Chen Y, Kang J, Lai H (2013) Rectal villous adenoma with McKittrick-Wheelock syndrome: report of a rare case. Viszeralmedizin 29:55-58

5. van Esch S, de Wit Marc van Milligen, van Laarhoven K, Rensma PL (2012) Episodic electrolyte disorders and renal failure due to a rare disease: the McKittrick-Wheelock syndrome. Clin Kidney J 5:166-167

6. Wakeman CJ (2010) Giant villous adenoma presenting as McKittrick-Wheelock syndrome and pseudo-obstruction. Med J Aust 192:225-227

7. Pucci G, Rondelli F, Avenia N, Schillaci G (2013) Acute renal failure and metabolic alkalosis in a patient with colorectal villous adenoma (McKittrick-Wheelock syndrome). Surgery 154:643-644

8. Moya P, Armananzas Ruiz L, Santos Torres J et al (2012) Acute renal failure and chronic diarrhea: McKittrick-Wheelock syndrome. Acta Gastroenterol Latinoam 42:56-58

9. Choi WH, Ryuk J, Kim HJ et al (2012) A case of giant rectal villous tumor with severe fluid-electrolyte imbalance treated by laparoscopic low anterior resection. J Korean Surg Soc $82: 325-329$ 